\title{
Impact of Work Life Balance on Employee Job Satisfaction in Private Banking Sector of Karachi
}

\author{
Sobia Shujat \\ Lecturer at Bahria University Karachi Campus \\ Farooq-E-Azam Cheema \\ Dean Management Sciences at the Institute of Business \& Technology (Biztek) \\ Faryal Bhutto \\ MBA Scholar at Bahria University Karachi Campus
}

\begin{abstract}
Purpose-The core purpose of this study is to analyze the impact of work life balance on employee job satisfaction in private banking sector of Karachi. The data were collected keeping in consideration features such as gender, age, managerial position and tenure of job. Factors involved are job satisfaction and work life balance with respect to flexible working conditions, work life balance programs, employee intention to change/leave job, work pressure/stress and long working hours.

Methodology/Sample- A total of 300 questionnaires were distributed out of which 273 were returned back after filling. The selected method for sampling in this research is snowball sampling. Data were collected using both primary and secondary sources. Primary data were collected through questionnaires. The data was analyzed using SPSS, test applied was correlation. Findings-The findings suggest that work life balance has very less impact on employee job satisfaction in private commercial banking sector of Karachi. The reason of such results may be due to the uncertain conditions, high inflation and unemployment rate in Pakistan.

Practical Implication- This research can be beneficial for the banking sector to improve their policies, benefits programs and pay structures to attract, recruit and retain more capable candidates. The results of this research shows that even in the metropolitan city like Karachi, employees are not aware of issues like job satisfaction and work life balance that is undoubtedly a basic right. People are contended as far as they have job, rest of the things do not seem important to them. This research can be utilized as a light for banks to pay attention to such factors, because their benefits are not only for employees but can benefit banks in the long run especially in maintain work force turnover.
\end{abstract}

Keywords : work life balance, job satisfaction, turnover rate, banking sector

\section{Jel classification :}

\footnotetext{
* The material presented by the author does not necessarily portray the viewpoint of the editors and the management of the Institute of Business \& Technology (Biztek) or Bahria University.

* Sobia Shujat : sobiashujaat@bimcs.edu.pk

* Farooq-E-Azam : dr.cheema@ibt.edu.pk

*Faryal Bhutto : snowwhite2687@gmail.com

(C) JMSS is published by the Institute of Business and Technology (Biztek). Main Ibrahim Hydri Road, Korangi Creek, Karachi-75190, Pakistan.
} 


\section{INTRODUCTION}

The rapid economic growth and development in the world has created new activities and open new doors for all the business organizations. The globalization trend has put the organizations hard to retain their competitive advantage. This trend has also affected the banking sector. Banking sector become more competitive. The changes in business activities bring change in culture and perception of the employees. Organizational changes due to downsizing, mergers/ acquisitions and radical changes in technology have changed the work setups. The employees in present are more involved in their jobs than in the last decade. The long working hours, work pressure, high demanding jobs, use of sophisticated technology made it difficult for employees to keep a balance between their job and work commitments (Nadeem and Abbas 2009).

Businesses are facing increasing demands to raise efficiency and becoming more responsive to customers and employees. No longer is it just a matter of remuneration and promotional prospects; job seekers are increasingly making employment decisions on how well their current or potential workplace can support a balance between personal lives and paid occupation (Tanvi and Fatama 2012). Pakistan is no more exception in this regard. Metropolis of the country like Karachi being considered as very busy and fast moving city and the work load and pressure and long working hours affects the level of employee job satisfaction.

Considerable research has already been conducted on work life balance and employee satisfaction in developed countries. Developing countries have also started paying+ attention on this front to increase employee job satisfaction. In Pakistan much research has been conducted on this issue and more efforts are being suggested to the bigger organizations especially the banking sector where longer working hours is a particular norm, to restore a work-life balance for the better good of the social and family life of the workforce. For instance, a study was conducted in Pakistan by Nadeem and Abbas, (2009) to discover the relationship among work life conflict and employee job satisfaction at all levels of the management in public and private organizations. Findings showed that job satisfaction at top level of management has negative correlation with family to work interference, family to work interference and stress and job satisfaction has positive correlation with job autonomy. Job satisfaction at the middle level of employees decreases when work life conflict and stress increases. Job satisfaction at the lower level of employees has negative correlation with stress and family to work interference and positive correlation with job autonomy.

Objective of this study is, thus, to examine the impact of work life balance on employee job satisfaction and to identify which factors of work life balance have more influence on employee job satisfaction in banking sector. This research can be helpful for banks to identify the factors which influence the employee work-life balance and the job satisfaction in the result. And to take measures to restore this balance.

Accordingly, following are the hypothesis to be tested for this study:

- $\mathrm{H}_{1}$ : There is no effect of long working hours on employee job satisfaction.

- $\mathrm{H}_{2}$ : There is no effect of flexible working condition on employee job satisfaction.

- $\mathrm{H}_{3}$ : There is no effect of work pressure on employee job satisfaction.

- $\mathrm{H}_{4}$ : There is no effect of change of job on employee job satisfaction.

- $\mathrm{H}_{5}$ : There is no effect of work-life balance programs on employee job satisfaction.

\section{LITERATURE REVIEW}

Literature shows that managers have valuable role in encouraging employees to manage their work and life activities. Strong relationship exists between work life balance and employee satisfaction, hence companies should make policies and programs for employees 
on work life balance. Managers can apply different roles of leadership to manage employees work life balance and provide success to the company (Rani et al 2011). When employees are not clear about their roles to be performed then employees are unable to meet organizational goals and it also has an impact on their personal life and employees become dissatisfied towards their job and organization faces lack of effectiveness.

Work-life balance policies and family supportive cultures have been observed in France and Japan also (Aybars 2007, Cole 2006). There is a wide variety of work-life balance initiatives for employees being incorporated by organizations and include flexible work hours, job sharing, parental leave on-site child care facility and telecommuting (Hartel et al. 2007). Studies suggest that in absence of work-life balance, employees' dissatisfaction increases.

However it is found that when employees' need in respect of creating a work-life balance is met by different organizational programmes they show higher job satisfaction and organizational commitment (Gregory and Milner 2009). A study was conducted in Pakistan by Nadeem and Abbas, (2009) to discover the relationship among work life conflict and employee job satisfaction at all levels of the management in public and private organizations. Findings showed that job satisfaction at top level of management has negative correlation with family to work interference, family to work interference and stress and job satisfaction has positive correlation with job autonomy. Job satisfaction at the middle level of employees decreases when work life conflict and stress increases. Job satisfaction at the lower level of employees has negative correlation with stress and family to work interference and positive correlation with job autonomy.

Hanglberger (2010) studied the effect of work-life balance, specifically working hours on employees' job satisfaction and finds a positive relationship between them. The same was analyzed by Gash et al. (2010) for women in UK and Germany and the findings supported Hanglberger studies, showing a positive effect of reduced working hours on employees' life satisfaction. Another study (Malik et al. 2010) was conducted in Pakistan to investigate the relationship between work-life balance, job satisfaction and turnover intentions among medical professionals in hospitals.

The level of employees' job satisfaction increases by many factors and when employees are satisfied with their work, they feel motivated (Noor, 2011). The demand of employees work life balance is increased by change in trends in the business such as change in organizations structure, diversity of work force and female employees working in organizations. Organizations should provide work life balance facilities to their employees so that employees can perform their duties effectively and leads organization to the success (Parvin and Kabir, 2011).

Another study by Dev 2012, conducted in India indicates that work-life balance is significantly correlated with job satisfaction in the banking sector. It suggested that female employees should be given more facilities such as flexi time, job sharing, child care, etc to gain their organizational commitment. It was revealed that those doctors who are better in managing their work-life shows higher satisfaction with jobs and less turnover intentions. Job satisfaction has negative correlation with work stress, family to work interference and work to family interference but have positive correlation with workload. Employees' productivity is reduced and their turnover and absenteeism are increased due do work life strain and most of the institutions also complain that they can't much facilitate their employees to balance their work and family responsibilities. Fatima and Sahibzada (2012) conducted a study on work-life balance in the universities. They concluded that due to heavy workload in universities, staff becomes dissatisfied. Hence, universities should develop strategies that could facilitate faculty needs to balance between work and life activities to achieve competitive advantage.

A study was conducted by Maren et al. (2013) to analyze work-life balance and 
job satisfaction among teachers exposed a negative relationship between work-life conflicts and job satisfaction. The study suggested that if organizations offer facilities to reduce work-life conflicts, it will lead to improvement in employees' job satisfaction. Chahal et al. (2013) suggested to increase the efficiency of the employee's bank should timely appraise their employees and encourage them to work hard because satisfied employees are reason for the success of the organization. When employees are satisfied with their jobs they become loyal and committed to the organization. Saleem et al (2013) say that organization should make strategies and policies that will help employees to have clear understanding regarding their job tasks and objectives and if employees are not satisfied with their job they will not pay attention to their work and will not make customers happy.

\section{RESEARCH METHODOLOGY}

The data was collected through snowball sampling method A total of 300 questionnaires were distributed to private commercial banks of Karachi out of which 273 were returned back after filling. $86.45 \%$ of the respondents were of non-managerial level whereas $13.55 \%$ of respondents were of middle level managers. $69.96 \%$ respondents were male and $30.04 \%$ were female. 39 respondents belonged to executive level and 21 belonged to operational level. $12.09 \%$ respondents were of less than 25 years of age, $47.62 \%$ respondents were of 25 to 35 year of age, $32.97 \%$ of the respondents were of 36 to 45 years of age, while $7.33 \%$ respondents were of 46 to 55 age groups.

Primary data were collected through questionnaires with 5 point likert scale where $\mathrm{A}=$ strongly disagree, $\mathrm{B}=$ somewhat disagree, $\mathrm{C}=$ neutral, $\mathrm{D}=$ somewhat agree, $\mathrm{E}=$ strongly agree. While secondary data was collected from books, magazines, research journals and web sites etc. The data was analyzed using SPSS 19 version, the test applied was Correlation Pearson's Product to analyze the relation between work life balance and job satisfaction.

\section{DATA ANALYSIS}

The following results show the correlation of work life balance on employee job satisfaction:

Correlations

\begin{tabular}{|ll|r|r|}
\hline & & Long working \\
& & job satisfaction & \multicolumn{2}{c|}{ hrs } \\
\hline job satisfaction & Pearson Correlation & 1 & -.085 \\
& Sig. (2-tailed) & & .164 \\
& N & 273 & 273 \\
\hline Long working hrs & Pearson Correlation & -.085 & 1 \\
& Sig. (2-tailed) & .164 & \\
& N & 273 & 273 \\
\hline
\end{tabular}

The correlation between the long working hours and job satisfaction is $r=-.085$. Hence, the first null hypothesis $\mathrm{H}_{1}$ is accepted. This coefficient shows that there is weak and negative relationship between the employees working hours and the job satisfaction. So, there is insignificant relation between long working hours and job satisfaction and it is concluded that as long working hours have weak relation so it has no impact on the level of employee's job satisfaction in banking sector but long working hours have negative relation so bank can increase employee's job satisfaction by reducing working hours of employee's. 
Correlations

\begin{tabular}{|ll|r|r|}
\hline & & job satisfaction & $\begin{array}{c}\text { Flexible working } \\
\text { conditions }\end{array}$ \\
\hline job satisfaction & Pearson Correlation & 1 & .003 \\
& Sig. (2-tailed) & .956 \\
& N & 273 & 273 \\
\hline Flexible working conditions & Pearson Correlation & .003 & 1 \\
& Sig. (2-tailed) & .956 & 273 \\
& N & 273 & \\
& &
\end{tabular}

The correlation between the flexible working conditions and employees job satisfaction is $\mathrm{r}=.003$. Hence, the second null hypothesis $\mathrm{H}_{2}$ is also accepted. This coefficient shows that there is very weak and positive relation between the flexible working conditions and job satisfaction among employees. So, there is insignificant relation between the flexible working conditions and employee's job satisfaction and it is concluded that as flexible working conditions have very weak relation so it has no impact on the level of employees' job satisfaction in banking sector. However banks can increase the level of employee's job satisfaction by increasing flexible working conditions to employees.

Correlations

\begin{tabular}{|ll|r|r|}
\hline & & \\
& & job satisfaction & work pressure \\
\hline job satisfaction & Pearson Correlation & 1 & -.033 \\
& Sig. (2-tailed) & & .582 \\
& N & 273 & 273 \\
\hline work pressure & Pearson Correlation & -.033 & 1 \\
& Sig. (2-tailed) & .582 & 273 \\
\hline
\end{tabular}

The correlation between the work pressure and employee's job satisfaction is $r=-.033$. Hence, the third null hypothesis $\mathrm{H}_{3}$ is also accepted. This coefficient shows that there is weak and negative relation between the work pressure and employees job satisfaction. So, there is insignificant relation between the work pressure and job satisfaction and it is concluded that as work pressure have negative relation with employee's job satisfaction, banks can reduce work pressure among employees to increase employees job satisfaction. However work pressure can be decreased by allocating job duties according to the employees skills.

Correlations

\begin{tabular}{|ll|r|r|}
\hline & & job satisfaction & WLB programs \\
\hline job satisfaction & Pearson Correlation & 1 & -.083 \\
& Sig. (2-tailed) & & .170 \\
& N & 273 & 273 \\
\hline WLB programs & Pearson Correlation & -.083 & 1 \\
& Sig. (2-tailed) & .170 & 273 \\
& N & 273 & \\
\end{tabular}


The correlation between the work life balance programs and employees job satisfaction is $\mathrm{r}=.083$. Hence, the fourth null hypothesis $\mathrm{H}_{4}$ is also accepted. This coefficient shows that there is weak and positive relation between work life balance programs and employee job satisfaction. So there is insignificant relation between the work life balance programs and employee job satisfaction. Therefore, it is concluded that as work life balance programs have positive relation with employee job satisfaction. However, banks can increase the level of satisfaction of employees by increasing employees work life balance programs.

Correlations

\begin{tabular}{|ll|r|r|}
\hline & & job satisfaction & Change of job \\
\hline job satisfaction & Pearson Correlation & 1 & -.021 \\
& Sig. (2-tailed) & & .735 \\
& N & 273 & 273 \\
\hline Change of job & Pearson Correlation & -.021 & 1 \\
& Sig. (2-tailed) & .735 & 273 \\
\hline
\end{tabular}

The correlation between the employees intention to leavelchange the job and job satisfaction is $r=-.021$. Hence, the fifth null hypothesis $\mathrm{H}_{5}$ is also accepted. This coefficient shows that there is weak and negative relation between change of job and employees job satisfaction. So there is insignificant relation between the employee's intention to leave job and job satisfaction. However, employee's job satisfaction can be increased by reducing employee's intention to change or leave the job by providing certain work life balance facilities.

\section{DISCUSSION}

According to this research work pressure have negative and weak relation with employees job satisfaction in private banking sector of Karachi. Previous researches also support findings of this study. For example, Nadeem and Abbas, (2009) found in their study that work pressure/stress is negatively correlated with job satisfaction in both private company LMKR and public company NADRA. Saleem et al. (2013) found in their study that job stress have very low impact on job satisfaction of employees in banking sector of Bahawalpur. Ashfaq et al. (2013) also found that work pressure also has weak relation with employee job performance in banking sector of Pakistan. Although work pressure has insignificant impact on job satisfaction, organizations can promote employee job satisfaction by distributing job duties according to the employee's skills and managers should also clarify their tasks to each employee so that they can perform their work on time to reduce their work pressurelstress. This point is also in lines with the findings of this study.

This study has also found out that there is positive relation of work life balance programs on employee job satisfaction in banking sector of Karachi. It is supported by other studies also. For example, Ueda, (2012) concluded that work life balance programs have positive and significant effect on employee job satisfaction of full time and part time employees working in business organizations of Japan. According to findings of this study these programs help employees to reduce their work burden and they will effectively perform their job and not job activities. Accordingly, banking sector can increase employee's job satisfaction by increasing work life balance programs for employees, which is likely to help them manage their job and family.

Likewise, the study has found that long working hours have negative and weak relation with employee's job satisfaction in private banking sector of Karachi. Long working hours do have much impact on employee's job satisfaction level because employees of Karachi banks have made it a norm to work long hours and give more priority to their job 
activities than non job activities in their life. In this way, this study contradicts with the work of Chahal et al. (2013) that found that $62.5 \%$ of employees in Canara bank in delhi NCR were dissatisfied with their job due to long working hours. However, work of Purohit, (2013) supports findings of this study that shows that $80 \%$ of the IT companies of Pune region in India practiced flexible time under the head of flexible working conditions because in IT companies employees work in day and night shifts.

\section{CONCLUSION}

The purpose of this study was to examine the impact of work life balance on employee job satisfaction and to identify which factor of work life balance have more influence on employee job satisfaction in banking sector of Karachi. The research findings show that work life balance have not much impact on employee job satisfaction and some factors of work life balance such as employee intention to leave job, work pressure and long working hours have negative relation with employee job satisfaction and work life balance programs and flexible working conditions have positive relation with employee job satisfaction. It is found out that the organizations can face multiple problems if their workforce satisfaction level is lower. It is essential that HR departments are responsive to the needs and constantly changing requirements of workforce and the effect of environmental issues in order to improve programs and policies. It also saves cost of hiring by improving employees retention. In case of research conducted in private banking sector of Karachi, the factors which were supposed to have greater impacts on employee job satisfaction and work life balance does not turn out to be effective. In this research, the null hypothesis of all the factors of work life balance with job satisfaction is accepted. There could be many reasons behind it i.e. the culture of Pakistan where one bread earner leads a family, the high inflation rate and fewer opportunities of jobs make employees to work on compromised benefits and salaries. These factors could be the reason as why the results of this study are different than the rest of world.

\section{REFERENCES}

1. Aarti, C., Seema, C., Bhawna, C., and Jyoti, C., (2013). Job Satisfaction Among Bank Employees: An Analysis Of The Contributing Variables Towards Job Satisfaction, International Journal of Scientific \& Technology, 2.

2. Clarke, M., Koch, L., and Hill E. (2004), The work-family interface:Differentiating balance and fit, Family and Consumer Sciences Research Journal, 33(2).

3. David, C., (2003), Managing Work-life Balance: A Guide for HR in Achieving Organisational and individual change.chartered intitiute of personal and development, CIPD house, camp road, London.

4. Dev, G.N., (2012), Employees' perception on work life balance and its relation with job satisfaction in Indian public sector banks, International Journal of Exclusive Management Research,2(2), 1-13.

5. Gash, V., Mertens, A., Romeu, G. L., (2010), Women between part-time and full-time work: The influence of changing hours of work on happiness and life-satisfaction, SOEP Papers No. 268, DIW Berlin.

6. Gregory, A. and Milner, S. (2009), Editorial: Work-life Balance: A Matter of Choice, Gender, Work \& Organization.

7. Hanglberger, D., (2010), Arbeitszufriedenheit und flexible Arbeitszeiten - Empirische Analyse mit Daten des Sozio-oekonomischen Panels, SOEP Papers No. 304, DI Berlin.

8. Hanif, A.M., (2002). X-efficiency Analysis of Commercial Banks in Pakistan: A Preliminary Investigation, The Pakistan Development Review,41(4) 567-580.

9. Resourcing, H. (2005), The case for work/life balance: Closing the gap between policy and practice. Hudson Australia and New Zealand available on www.hudson.com

10. Idiab, A., Haron, M., Sabri, M., and (2011), Commercial Banks \& Historical Development, Journal of Applied Sciences Research. 7(7): 1024-1029. 
11. Mahamuda, P.M., and Nurul, K. M. M. (2011), Factors Affecting Employee Job Satisfaction of Pharmaceutical Sector, Australian Journal of Business and Management Research, .1(9), 113-123.

12. Malik, M.I., Gomez, S.F., Ahmad, M., and Saif, M. I., (2010), Examining the relationship of Work Life Balance, Job Satisfaction and Turnover in Pakistan, International Journal Sustainable Development, 2(1) 27-33.

13. Manisha, P., (2013), A Comparative Study of Work Life balance in various Industrial Sector in Pune Region, International Journal of Marketing, Financial Services \& Management Research. 2(3).

14. Maren, R., Pitarelli, F., and Cangiano, F. (2013), Work-life balance and job satisfaction among teachers, Interdisciplinary Journal of Family Studies, 18, 51-72.

15. Noor, F., and Shamim, A., (2012), An Empirical Analysis of Factors Affecting Work Life Balance among University Teachers: the case of Pakistan, Journal of International Academic Research, .12(1).

16. Noor, K.M. (2011), Work-Life Balance and Intention to Leave among Academics in Malaysian Public Higher Education Institutions, International Journal of Business and Social Science, 2(11).

17. Rehman, Hafeez, Ahmed, and Saima, (2008), An Empirical Analysis of the Determinants of Bank Selection in Pakistan, Pakistan Economic and Social Review. 46(2), 147-160.

18. Sabra, N.M., Abbas, and Qaisar, (2009), The Impact of Work Life Conflict on Job Satisfactions of Employees in Pakistan, International Journal of Business and Management. 4( 5).

19. Sageer, Rafat,A., Sameena, Agarwal, and Puja, (2012), Identification of Variables Affecting Employee Satisfaction and their Impact on the Organization, Journal of Business and Management, 5, 32-39.

20. Saif, Iqbal,M., Malik, Imran,M., Zahid, M.,(2011), Employee Work Satisfaction and Work - Life Balance: A Pakistani Perspective, Interdisciplinary Journal of Contemporary Research in Business, 3(5).

21. Saira, A., Zahid, M, and Mehboob, A., (2013). Impact of Work-Life Conflict and Work over Load onEmployee Performance in Banking Sector of Pakistan, Middle-East Journal of Scientific Research. 14 (5), 688-695.

22. Sakthivel, R., Kamalanabhanb, and Selvarania, (2011), Work Life Balance Reflections on Employee Satisfaction, Serbian Journal of Management. 6 (1), 85 - 96.

23. Saleem, Saba. Majeed, Sadia. Aziz, Tariq and Usman, (2013), Determinants of Job Satisfaction among Employees of Banking Industry at Bahawalpur, Journal of Emerging Issues in Economics, Finance and Banking, 1(2).

24. Sehgal and Shallu, (2012), Job Satisfaction of Bank Employees in Shimla, International Journal of Marketing, Financial Services \& Management Research 1(7).

25. Tanvi, N.M., and Fatama, Z.K., (2012), Work-life balance: Is it still a new concept in privatecommercial banking sector of Bangladesh, International Journal of Research Studies in Management. 1(2), 57-66.

26. Ueda, and Yutaka, (2012), The Relationship between Work-life Balance Programs and Employee Satisfaction: Gender Differences in the Moderating Effect of Annual Income, Journal of Business Administration 1(1). 